\title{
O judiciário e a saúde mental no trabalho
}

\author{
Judicial system and mental health at work
}

\author{
${ }^{1}$ Desembargador do Tribunal Regional do \\ Trabalho da $9^{\mathrm{a}}$ região - Curitiba-PR \\ Contato: \\ Alameda Doutor Carlos de Carvalho, 528 - \\ Curitiba-PR \\ CEP: $80430-180$ \\ E-mail: \\ ricardofonseca@trt9.jus.br
}

Recebido: 01/03/2011

Aprovado: 14/03/2011
A medicina do trabalho informa o direito laboral de maneira substancial, eis que a CLT dedica ao assunto um capítulo próprio (Capítulo 5).

O diploma obreiro, porém, como se sabe datado de 1943, disciplina de forma expressa tão somente a tutela da saúde física do trabalhador, prescrevendo medidas de prevenção contra agentes químicos, físicos e biológicos comuns ao meio ambiente do trabalho. Há que se ressaltar, entretanto, que, desde então, a CLT já se voltava à higidez mental dos trabalhadores ao limitar a duração do trabalho e estabelecer, por exemplo, a jornada de oito horas, a carga semanal de quarenta e oito horas, depois reduzida pela Constituição a quarenta e quatro, e férias de trinta dias.

Os chamados direitos tutelares do trabalho também são estendidos à proteção de mulheres e crianças, bem como a algumas categorias cuja jornada é reduzida em razão do notório desgaste que lhes impõem as respectivas atividades, citando-se, os telefonistas e os bancários (6 horas), os jornalistas (5 horas), os médicos (4 horas) etc.

Apenas a partir da Constituição de 1988 esta proteção à saúde do trabalhador assume a perspectiva do campo dos chamados direitos de personalidade cuja abrangência implica cuidados com a dignidade, a privacidade e a intimidade das pessoas. A Carta Política estabeleceu no artigo $5^{\circ}$, X, que: "são invioláveis a intimidade, a vida privada, a honra e a imagem das pessoas, assegurado o direito a indenização pelo dano material ou moral decorrente de sua violação”.

As relações entre capital e trabalho sofreram significativa revolução, mormente no que concerne ao exercício do poder diretivo do empregador, que se moldou historicamente em torno do direito de defesa do patrimônio e da hierarquia inerentes à dinâmica empresarial. Padrões outrora considerados normais, na forma do exercício desse poder passaram a ser reavaliados.

O direito de revista dos empregados, antes tranquilamente assegurado pelos estudiosos, sofre hoje severas restrições por parte dos Tribunais por implicar abuso contra a esfera de proteção dos indivíduos delineada pelo dispositivo constitucional acima transcrito.

Os estudos de Marie-France Hirigoyen sobre o assédio moral repercutiram profundamente nas relações interpessoais e coletivas nas empresas, tanto que grande parte dos processos que tramitam na Justiça do Trabalho discutem os limites do exercício do poder diretivo do empregador sob a égide da integridade psíquica e moral do trabalhador, tornando-se corriqueira a constatação da ocorrência de desvios de tal exercício, que acarretam indenizações por dano moral aos lesados. 
Recentemente, os próprios métodos de gestão, caracterizados, em algumas ocasiões, por medidas rigorosas, visando ao atingimento de metas ou à melhoria de desempenho da equipe, têm sido considerados abusivos. É o que ocorre quando se verifica a exposição daqueles que não atingem as expectativas estabelecidas a condições por vezes até degradantes. Trata-se, nessas hipóteses, do assédio moral coletivo ou organizacional, que vem sendo combatido sistematicamente pelo Ministério Público do Trabalho por meio das ações civis públicas, bem como pelos próprios trabalhadores prejudicados, que findam por obter reparações também de natureza indenizatória concernentes a sua integridade moral e psíquica, mesmo que a ameaça que lhes aflija se revele de modo virtual, potencial, por aquilo que também se convencionou denominar gestão injuriosa.

O nexo de causalidade ou concausalidade entre o trabalho e doenças de natureza psíquica ou psicossomáticas, outrossim, assumiu relevância. Com efeito, o Decreto presidencial 3.048/99, regulamentando o artigo 20 da Lei 8.213/91, criou amplo rol de doenças ocupacionais, inovando em muitos aspectos. Destaque-se o fato de que doenças que sempre foram relegadas pelos médicos do trabalho, por não decorrerem diretamente deste, passaram a ser consideradas até mesmo quando a atividade laboral tão somente se faz sentir como o fator agravante dos sintomas a elas inerentes. A hipertensão, a depressão e outras doenças, desde que demonstrado o nexo de causalidade, são agora vistas pela Previdência como enfermidades do trabalho.

Flagrante avanço também cedeu na legislação brasileira com o advento do nexo epidemiológico de causalidade, por meio da Lei 11.430/2006. A norma em questão determina que, a partir de estudos estatísticos pelo INSS, certas categorias econômicas, em razão da própria peculiaridade das atividades, dos respectivos agentes químicos, físicos ou biológicos nocivos que a caracterizam, têm contra si uma presunção relativa de que o nexo de causalidade ocorreu. A consequência, portanto, é significativa em termos processuais, visto que, na prática, basta o trabalhador alegar a doença e demonstrar a sua alta ocorrência na categoria, conforme estudos prévios do INSS, para gerar o direito em tese, cabendo à empresa demonstrar por qualquer meio de prova a inexistência do nexo presumido. Verifica-se, assim, verdadeira inversão do ônus da prova em favor do trabalhador e da própria Seguridade Social.

Seguem abaixo, algumas decisões que ilustram o que se disse até aqui:

EMENTA: ADMINISTRAÇÃO POR ESTRESSE - DANO MORAL. A adoção de estratégias empresariais agressivas, baseadas no cumprimento de metas elevadas, aliadas a imposição de jornadas exaustivas, sob a constante ameaça da perda do emprego, com a submissão dos trabalhadores a intensa pressão psicológica, vem sendo classificada pela doutrina como "ADMINISTRAÇÃO POR ESTRESSE" ou assédio organizacional, técnica gerencial voltada exclusivamente a obtenção do lucro, em prejuízo da dignidade humana dos empregados, representando uma espécie de assédio moral coletivo, por afetar, indistintamente, um grupo de empregados, expondo-os a um meio-ambiente de trabalho degradado pelas constantes humilhações praticadas pelos superiores hierárquicos. Recurso ordinário conhecido e parcialmente provido. Vistos, relatados e discutidos os presentes autos de recurso ordinário, [...] acordam os desembargadores da $1^{\underline{a}}$ Turma do Tribunal Regional do Trabalho da $16^{a}$ Região, por unanimidade, conhecer do recurso e, no mérito, por maioria, dar-lhe provimento parcial, nos termos deste voto. (TRT 16 $\underline{\text { a }}$ R. - 00880-2008-015-16-00-1-RO (74492) - Rel. JOSÉ EVANDRO DE SOUZA - data de publicação: 12/03/2010).

EMENTA: ASSÉDIO MORAL ORGANIZACIONAL. ADMINISTRAÇÃO POR ESTRESSE. PRÁTICA GENERALIZADA, OFENSIVA AOS DIREITOS DE PERSONALIDADE DOS EMPREGADOS, VISANDO INCREMENTO DOS LUCROS. PRENDAS VEXATÓRIAS AOS VENDEDORES QUE PRODUZISSEM MENOS. CARACTERIZAÇÃO. INDENIZAÇÃO POR DANOS MORAIS DEVIDA. QUANTUM REDUZIDO. O assédio moral organizacional, ou administração por estresse, se diferencia do assédio moral clássico (interpessoal) por caracterizar prática generalizada da empresa, ofensiva aos direitos de personalidade dos empregados, visando os lucros. Se a empresa estabelece ou, da mesma forma, se é conivente com o estabelecimento de prendas vexatórias aos empregados que produzem menos, está caracterizado o assédio moral organizacional, sendo devida indenização mesmo ao empregado que, concretamente, não teve que "pagar prenda", pois se sujeitou a ambiente de trabalho hostil, sofrendo pressão psicológica inadmissível. Contudo, a circunstância do reclamante não ter sido vítima direta das "prendas" implica em redução do quantum indenizatório. Recurso ordinário conhecido e parcialmente provido. (TRT 16 $\underline{\text { a }}$ R. - 00743-2008-001-16-00-4 - Rel. JOSÉ EVANDRO DE SOUZA data de publicação: 28/04/2010)

EMENTA: TENTATIVA DE SUICÍDIO. TRANSTORNO MENTAL. TRABALHO COM BENZENO E HIDROCARBONETOS. NEXO TÉCNICO PREVIDENCIÁRIO. ÔNUS DO EMPREGADOR DE AFASTAR A PRESUNÇÃO DO NEXO DE CAUSALIDADE. A exposição por anos ininterruptos às substâncias químicas benzeno e hidrocarboneto ocasiona transtornos mentais e de comportamento, sendo o nexo de causalidade entre a doença e o labor presumido, por força do Decreto 3.048/99 e da Instrução Normativa INSS/PRES n⿳ำ 31 . No caso concreto, ausente prova suficiente para afastar a presunção legal, bem como a existência de ato ilícito pela reclamada, qual seja, deixar de fornecer e fiscalizar o uso de EPIs, o que deveria ser observado com maior rigor, ante a natureza de risco da atividade. A opinião de perito não é suficiente para elidir a presunção, diante das provas robustas existentes nos autos em sentido contrário. Inteligência do art. 436, do CPC. Presentes, pois, o ato 
ilícito, o nexo de causalidade presumido e o dano (incapacidade para o trabalho) devida a responsabilização civil do empregador.(TRT 9a R. -07714-2008-664-09-00-3-ACO-38157-2010 - 2A. TURMA - Relator: RICARDO TADEU MARQUES DA FONSECA - Publicado no DEJT em 30/11/2010)

EMENTA: DANO MORAL - RETALIAÇÃO DO EMPREGADO POR AJUIZAMENTO DE AÇÃO TRABALHISTA EM FACE DA EMPRESA - DESIGNAÇÃO PARA FUNÇÃO E LOCAL DIVERSOS DO CONTRATADO E EM CONDIÇÕES PRECÁRIAS - ASSÉDIO MORAL - INDENIZAÇÃO. Empregado contratado como auxiliar de produção, que após ter ajuizado ação trabalhista em face da empresa foi designado para laborar na portaria, local que, por suas condições, era inadequado e incompatível com a dignidade da pessoa humana e em função desnecessária, porquanto não havia na empresa a função de porteiro, sofre assédio moral. Ausente prova de que a designação se fez necessária após a participação do empregado em curso de readaptação profissional, em virtude de acidente do trabalho, considera-se que foi em retaliação ao exercício do direito fundamental de ação. Danos morais reconhecidos. Recurso a que se nega provimento para manter a sentença que condenou a ré em indenização por danos morais. (TRT 9a R. -03695-2009662-09-00-4-ACO-01728-2011 - 2A. TURMA - Relator: MARLENE T. FUVERKI SUGUIMATSU - Publicado no DEJT em 25-01-2011)

Convém sublinhar, finalmente, que as meras reparações por dano moral não trarão resultados a médio e longo prazos para a melhoria das relações laborais, a tornar imprescindíveis medidas de caráter preventivo que, todavia, inexistem no ordenamento jurídico brasileiro no que se refere à saúde mental no trabalho. Seria, portanto, de todo conveniente a elaboração de norma regulamentar à semelhança do que ocorre com a prevenção da saúde física há décadas em nosso país. 